\title{
Relation between neuropsychological and neuroimaging findings in patients with late whiplash syndrome
} Bogdan P Radanov, Ivette Bicik, Jiri Dvorak, James Antinnes, Gustav K von Schulthess,
Alfred Buck
Department of Psychiatry, University of Berne, Inselspital, CH-3010 Berne,

Switzerland B P Radanov

Division of Nuclear Medicine, University Hospital Zuerich, CH-8091 Zuerich, Switzerland

I Bicik

G K von Schulthess A Buck

Department of Neurology, Wilhelm Schulthess Hospital, Lengghalde 2, CH-8008 Zuerich, Switzerland

J Dvorak

Department of Orthopedic Surgery, Ochsner Foundation Hospital, 1516 Jefferson Highway, New Orleans, Louisiana 70121, USA J Antinnes

Correspondence to: Dr BP Radanov, Department of Psychiatry, University of Berne, Inselspital, CH-3010 Berne, Switzerland. Telehone: 0041 316328811 ; fax 004131 63289 50; email

radanov@pupk.unibe.ch

Received 13 March 1998 and in revised form

24 August 1998

Accepted 23 September

1998

\begin{abstract}
Objectives-The interpretation of long term cognitive impairment after whiplash injury is still a problem for many physicians. On the grounds of nuclear medicine findings previous research speculated that brain damage is responsible for cognitive problems of patients with whiplash. To test this hypothesis the relation between neuroimaging and neuropsychological findings was analysed.
\end{abstract}

Methods-Twenty one patients (11 women, 10 men, mean age 42.2 (SD 8.6) years) with the late whiplash syndrome (average interval of trauma 26.1 (SD 20.7) months) referred for diagnostic action to the Department of Neurology were investigated. Assessment included computer assisted assessment of working memory and divided attention, neuroimaging (by the means of $\left[{ }^{99 \mathrm{~m}} \mathrm{Tc}\right]-H M P A O-S P E C T$, $\left[{ }^{15} \mathrm{O}\right]-\mathrm{H} 2 \mathrm{O}-\mathrm{PET}$ and $\left.\left[{ }^{18} \mathrm{~F}\right]-\mathrm{FDG}-\mathrm{PET}\right)$, testing of emotional functioning (depression and anxiety ratings), and pain intensity at the time of testing.

Results-On average, scoring on tests of cognitive functioning was very low. However, no significant correlations were found between regional perfusion or metabolism in any brain area and the scores of divided attention or working memory. By contrast, significant relations were found between indices of impaired emotional functioning (state anxiety) and divided attention. In addition, low scoring in divided attention was significantly correlated with pain intensity at the time of testing.

Conclusions-The present data do not provide evidence of a significant relation between detectable morphological or functional brain damage and impaired cognitive performance in the late whiplash syndrome. Results indicate triggering of emotional and cognitive symptoms on the basis of initial injury of the cervical spine.

(F Neurol Neurosurg Psychiatry 1999;66:485-489)

Keywords: brain damage, neuroimaging, neuropsychological testing, whiplash injury, working memory.

The so-called whiplash injury of the cervical spine is a benign condition with a reasonable rate of recovery ${ }^{12}$ and a lack of identifiable physical or neurological damage. ${ }^{12}$ However, various studies have reported impairment in cognitive performance in patients who had whiplash injury. ${ }^{3-7}$ Cognitive impairment of these patients is mainly concerned with attentional functioning of which divided attention is the most impaired aspect. ${ }^{4-7}$ Furthermore, considerable impairment was found in tasks requiring working memory. ${ }^{4}$ Working memory itself is a temporary information storage system which provides the possibility for holding several types of information at the same time. ${ }^{89}$ Accordingly, unhampered functioning of working memory is a necessary requirement for different aspects of attentional functioning including divided attention. ${ }^{8}{ }^{9} \mathrm{Re}-$ cent studies using functional MRI or PET in humans showed that the dorsolateral prefrontal cortex is the structure of the brain critically involved in tasks requiring working memory. ${ }^{10} 11$

Both PET and SPECT have been shown to be useful in the assessment of mild brain injuries (concussion) in which MRI or CT and clinical neurology failed to provide findings of detectable damage. ${ }^{12}{ }^{13}$ In these patients with mild traumatic brain injury deficits in cerebral perfusion were found in the rostral brain $\operatorname{areas}^{12}{ }^{13}$ which corresponded to neuropathological findings in the brain obtained by experimentally induced accelerationdeceleration trauma. ${ }^{14}$ Notably, in patients with mild brain injury perfusion deficits were significantly correlated with neuropsychological performance. ${ }^{12}{ }^{13}$ Moreover, follow up studies of mild traumatic brain injury showed regression of rostral perfusion deficits accompanied by improvement in neuropsychological performance. $^{13}$

Based on findings of impaired cognitive functioning of patients with whiplash, recent research suggested brain damage in those who had this injury. ${ }^{15}$ Using SPECT ${ }^{16}$ or PET ${ }^{15} 17$ the specific damage has been suspected in the parieto-occipital brain. However, by contrast with frontal brain damage, damage to parietooccipital areas is an uncommon finding in both experimentally induced accelerationdeceleration trauma ${ }^{14}$ and in patients who had mild brain injury. ${ }^{12}{ }^{13}$ In addition, it has recently been shown that both normal controls and patients with whiplash displayed parietooccipital perfusion or metabolism deficits on visual analysis. ${ }^{18}$ However, when analysed using statistical parametric mapping, discrete deficits in the frontal pole or putamen were found in patients with whiplash but not in controls. ${ }^{18}$ 
Considering the magnitude of these deficits PET and SPECT have been questioned as methods for assessing brain damage after whiplash. ${ }^{18}$

More recently it has been speculated that parieto-occipital hypoperfusion may be explained by activation of nociceptive afferents from the upper cervical spine. ${ }^{15}{ }^{17}$ However, previous imaging studies on cerebral representations of pain showed that pain had multiple representation which mainly involved rostral brain areas ${ }^{19} 20$ or basal ganglia (for example, the thalamus). ${ }^{20}$ In addition, previous imaging studies suspecting brain damage in patients with whiplash did not correlate the imaging findings with results from cognitive functioning. ${ }^{15-17}$ Correlational analysis between imaging techniques (PET or SPECT) and neuropsychological findings is necessary to clarify whether neuroimaging deficits may support the brain damage hypothesis as a basis of cognitive problems in whiplash. In the present study we employed a multidisciplinary study design (neuroimaging, testing of cognitive and emotional functioning, and clinical neurology) in patients with late whiplash syndrome to analyse in detail the relation between subjective and experimental findings on the basis of hypothesis guided research.

\section{Patients and methods}

Twenty one patients (11 women, 10 men, mean age 42.2 (SD 8.6) years, range 20-55 years) who had whiplash injury on an average of 26.1 (SD 20.7) months (range 6-48 months) were investigated. Seventeen patients were involved in litigation. Patients were fully informed about the purpose of the study, particularly concerning neuroimaging, and gave their informed consent. Based on previous research whiplash was considered a musculoligamental strain or sprain of the cervical spine due to hyperextension/hyperflexion without injury due to head contact, without loss of consciousness or post-traumatic amnesia or fractures or dislocations of the cervical spine. ${ }^{1221}$ None of the patients had injuries to other parts of the body during the accident leading to whiplash, previous neurological dysfunctions, head injury, or had treatment because of brain injury. No structural brain damage on MRI or CT was found in any of the patients. However, all patients complained of persistent head or neck pain and cognitive deficits.

The investigation consisted of:

(1) A structured interview by which details of the patient's history were collected and particular emphasis was put on pain intensity at the time of cognitive testing. For the latter purpose a scale from $0-10$ points (no pain to maximum pain) was administered.

(2) The following self-rating assessments of emotional functioning were employed: (a) The Beck depression inventory (BDI) in its German version. ${ }^{22} 23$ This well validated and reliable rating for assessing depressed mood consists of 21 items which are scored from zero to three points (range $0-63$ points). This inventory was employed because depressed mood may lead to diminished ability of mental effort, which is a necessary requirement to perform neuropsychological testing. ${ }^{24}$ For this reason patients with significantly depressed mood may show impairment while performing cognitive testing. Scores over 12 points on this inventory are indicative of depressed mood, the severity of which positively correlates with increased BDI values; (b) state-trait-anxietyinventory (STAI-X1 and STAI-X2) in its German version. ${ }^{25} 26$ State anxiety is situational anxiety which may change over time depending on life circumstances, whereas trait anxiety has been considered stable with respect to time and largely independent of the level of current stress. ${ }^{27}$ Trait anxiety is indicative of anxiety proneness, a factor which is reasonably correlated with neuroticism ${ }^{27}$ which is considered to influence the manner and seriousness of how symptoms are perceived or presented. ${ }^{28}$ Both STAI-X1 and STAI-X2, scores of which are significantly interrelated, contain 20 items which describe symptoms of anxiety or indicate the absence of anxiety symptoms. ${ }^{25} 26$ The patient is asked to report how she or he feels by indicating how often she or he experiences specific anxiety symptoms. There are four response choices (almost never, sometimes, often, and almost always) each being given a score ( $1=$ almost never to $4=$ =almost always). Items indicating the absence of anxiety symptoms are scored in reversed sequence. An overall score is calculated by totalling scores of individual responses. A score range for both STAI-X1 and STAI-X 2 is $20-80$ points.

(3) Cognitive performance was tested using a computer assisted test battery run on an IBM compatible computer equipped with a 14 inch black and white screen and a sound card. ${ }^{29}$ Patients were required to react as quickly as possible by pressing a button using their preferred hand. To exclude possible adverse effects on cognitive performance patients were asked to discontinue any medication at least 3 days before the testing procedure. For the purpose of this study the following tasks were considered salient: (a) Divided attention which requires a simultaneous and quick reaction to visual and acoustic stimuli and is evaluated as follows. The patient is presented a series of 100 matrices (11 degrees of visual angle) displayed on the screen, each for a duration of 3 seconds with an interstimulus interval of $500 \mathrm{~ms}$. The matrix consists of a regular array of 16 dots $(4 \times 4)$ with seven small crosses superimposed randomly on them. Whenever four superimposed crosses form a square, the patient should react. At the same time, the patient hears high and low beeps $(1000 \mathrm{~Hz}$ and $2000 \mathrm{~Hz})$ which alternate regularly. Sometimes a beep is followed by another with the same frequency, at which time the patient should react. In particular, adequate reaction on acoustic stimuli on this task requires sufficient functioning of working memory. The dependent variables are reaction times and omissions (scoring being $t$ value $\times t$ value). The score corresponding to the 50 th percentile on this task is $2500(50 \times 50) ;(b)$ working memory, in which the patient is presented with a series of 100 single digits in the middle of the screen. The patient has to 
Table 1 Test scores and pain intensity at the time of cognitive testing

\begin{tabular}{lll}
\hline Assessment & Mean score (SD) & Score range \\
\hline Beck depression inventory (BDI) score & $13.0(5.3)$ & $5-25$ \\
State anxiety (STAI-X1) score & $49.0(11.6)$ & $26-71$ \\
Trait anxiety (STAI-X2) & $42.4(9.8)$ & $26-64$ \\
Pain intensity at the time of testing & $3.9(2.8)$ & $0-8$ \\
Divided attention score & $1841.4(830.3)$ & $400-3074$ \\
Working memory score & $77.3(42.5)$ & $22.3-154.0$ \\
\hline
\end{tabular}

react when the digit presented on the screen is equal to the number preceding the last digit presented (for example, 4, 7, 3, 8, 3). The dependent variables for this task were reaction time, errors, and omissions (scoring $t$ value $\times t$ value $\times t$ value). Score corresponding to the 50 th percentile on this task is $125000(50 \times 50 \times 50)$ and is presented in the results cut by 1000 (50th percentile $=125.0$ ).

Before the testing procedure patients practised each single task until they stated that they were performing at their best. Both tasks were scored automatically, patients being compared with controls according to age, sex, and educational level. ${ }^{29}$

(4) Neuroimaging to assess cerebral perfusion was carried out using SPECT and PET. The tracers employed were [ $\left.{ }^{99 \mathrm{~m}} \mathrm{Tc}\right]$ hexamethylene propyleneamine oxime (HMPAO) and $\left[{ }^{15} \mathrm{O}\right]-\mathrm{H}_{2} \mathrm{O}$ respectively. Glucose metabolism was assessed with $\left[{ }^{18} \mathrm{~F}\right]$-fluoro-2-deoxy-Dglucose and PET. These three studies were performed on two different days, preferably both PET studies on the same day. The time interval between the PET and the SPECT studies was generally 2 days. All patients had to discontinue CNS acting medications for at least 3 days before neuroimaging studies.

The scans were performed as follows: $(a)$ SPECT was performed using a triple headed camera (Prism 3000, Picker International, Highland Heights, OH, USA) equipped with low energy, ultrahigh resolution fan beam collimators. Tomographic data were acquired 15-55 minutes after the intravenous injection of 550-650 MBq [ $\left.{ }^{99 \mathrm{~m}} \mathrm{Tc}\right]-H M P A O$. Transaxial images were reconstructed on a $128 \times 128$ matrix with a voxel size of $1.70 \times 1.70 \times 2.30$ $\mathrm{mm}$; (b) PET was performed using a whole body scanner (Advance, GE Medical Systems, Waukesha, Wisconsin, USA). $\left[{ }^{15} \mathrm{O}\right]-\mathrm{H}_{2} \mathrm{O}-\mathrm{PET}$ data acquisition started at the time of arrival of the water bolus in the brain and lasted for 1 minute. The injected activity ranged from 500-700 MBq. $\left[{ }^{18} \mathrm{~F}\right]-F D G-P E T$ data were acquired 40-60 minutes after the injection of 100-200 MBq $\left[{ }^{18} \mathrm{~F}\right]-\mathrm{FDG}$. All PET data were acquired in the $3 \mathrm{D}$ mode. Transaxial images of the brain were reconstructed using filtered back projection $(128 \times 128$ matrix, voxel size $2.34 \times 2.34 \times 4.25 \mathrm{~mm})$.

(5) Clinical evaluation consisted of a clinical neurological examination to exclude damage to the central or peripheral nervous system and was supplemented by conventional flexion/ extension radiographs and MRI examination of the cervical spine. The MRI was performed to exclude fractures or dislocations of the cervical spine.
Hypotheses

Based on previous research patients will display impairment on both divided attention and working memory tasks. ${ }^{4-7}$ Accordingly both these aspects will significantly correlate. At the same time patients showing deficits in divided attention and working memory will display diminished perfusion or metabolism in the areas of the brain found to be sites of working memory system (dorsolateral prefrontal cortex), ${ }^{10}{ }^{11}$ where lesions, if any, may be expected according to clinical ${ }^{12}$ or experimental reasearch. ${ }^{14}$ Accordingly regional tracer uptake in the cerebral areas corresponding to sites of the working memory system and test scores of divided attention and working memory will significantly correlate.

\section{Data analysis}

For the main purpose of the study (correlation between scores of cognitive testing and imaging findings) statistical analyses were performed using statistical parametric mapping (SPM95 software, MRC Cyclotron, London, UK, 1995). ${ }^{30}$ As a first step all studies were transformed into a standard stereotactic space. ${ }^{31}$ The correlation between the regional tracer uptake and the scores of divided attention and working memory were assessed by performing a linear regression on a voxel by voxel basis. Confounding effects caused by differing injected activities were removed by normalising each scan to a common whole brain average. The analysis assigned each voxel a $\mathrm{z}$ score representing the significance of the correlation. A z score $>0.01$ was chosen to indicate a significant correlation $(p<0.001)$ between the normalised tracer uptake and the scores of divided attention and working memory. The high threshold level has been used because the present was not an activation study, and the lower threshold would not adequately correct for multiple comparisons.

In addition, bivariate correlations were calculated between test scores of working memory and divided attention and scores of BDI, STAI-X1, STAI-X2 on the one hand and divided attention and working memory and pain intensity at the time of testing on the other. This analysis was performed to assess the relation between cognitive performance scores and emotional functioning and pain intensity. For this purpose Spearman correlation coefficient (two tailed test of significance) was performed using SPSS statistical package, version 6.1.1 (SPSS Inc, Chicago, USA, 1995).

\section{Results}

Neurological assessment did not find any deficit of the central or peripheral nervous system and radiological evaluation did not show dislocation, instability, or fractures of the cervical spine.

Results for BDI, STAI-X1, STAI-X2, and pain intensity at the time of testing and scores of divided attention and working memory are shown in table 1. Average scoring on STAI-X1 was high. In addition, patients on average scored low on tasks of divided attention and 
Table 2 Correlation coefficients between test scores and their significance values

\begin{tabular}{|c|c|c|c|c|c|}
\hline & STAI-X1 score & STAI-X2 score & Pain intensity at the time of testing & Divided attention score & Working memory score \\
\hline $\begin{array}{l}\text { BDI score } \\
\text { STAI-X1 score } \\
\text { STAI-X2 score } \\
\text { Pain intensity at the time of testing } \\
\text { Divided attention score }\end{array}$ & $r=0.4569, \mathrm{p}=0.037$ & $\begin{array}{l}r=0.6272, \mathrm{p}=0.002 \\
r=0.5664, \mathrm{p}=0.007\end{array}$ & $\begin{array}{l}r=0.2521, \mathrm{p}=0.270 \\
r=0.3510, \mathrm{p}=0.119 \\
r=0.3540, \mathrm{p}=0.115\end{array}$ & $\begin{array}{l}r=-0.1448, \mathrm{p}=0.531 \\
r=-0.4403, \mathrm{p}=0.046 \\
r=-0.1886, \mathrm{p}=0.413 \\
r=-0.5512, \mathrm{p}=0.010\end{array}$ & $\begin{array}{l}r=-0.3264, \mathrm{p}=0.149 \\
r=-0.3792, \mathrm{p}=0.090 \\
r=-0.3499, \mathrm{p}=0.120 \\
r=-0.0216, \mathrm{p}=0.926 \\
r=0.5662, \mathrm{p}=0.007\end{array}$ \\
\hline
\end{tabular}

working memory, which were significantly correlated (table 2).

Decreased tracer uptake was found in the paretal cortex in four patients. Using SPM95, significant correlations were found between both FDG-PET and HMPAO-SPECT $(r=0.711)$ and $\mathrm{H}_{2} \mathrm{O}-\mathrm{PET}$ and HMPAOSPECT $(r=0.731){ }^{32}$ However, no significant correlations between tracer uptake ([ $\left.{ }^{99 \mathrm{~m}} \mathrm{Tc}\right]-$ HMPAO-SPECT, $\left[{ }^{15} \mathrm{O}\right]-\mathrm{H}_{2} \mathrm{O}$, and $\left[{ }^{18} \mathrm{~F}\right]-\mathrm{FDG}-$ PET) and the scores of divided attention or working memory were found in any brain area $(\mathrm{z}<3.01, \mathrm{p}>0.001)$.

Significant correlations (table 2) were found between pain intensity at the time of testing and score of divided attention and between BDI score with STAI-X1 and STAI-X2 scores. Further significant correlations were found between state anxiety and trait anxiety (STAI-X1 and STAI-X2) and state anxiety (STAI-X1) and divided attention.

\section{Discussion}

This is the first study to assess the relation between functional neuroimaging data and cognitive performance of patients with what is referred to as the late whiplash syndrome. ${ }^{33}$ While studying this relation we considered results of previous research ${ }^{4-7}$ and applied scentifically acknowledged methods of cognitive testing in combination with advanced imaging techniques. ${ }^{29}$ All patients in the present study discontinued their medication before undergoing cognitive testing and neuroimaging studies. Thus results here may be interpreted without considering the possible adverse effects of medication on investigation procedures. We deliberately studied the relation between cognitive performance and neuroimaging in the late whiplash syndrome for the following reasons: cognitive impairment is a frequent complaint in the late whiplash syndrome but remains poorly understood by physicians. ${ }^{134}$ In addition, in most countries with established accident insurance programmes traumatic brain injury is a compensatable sequel. Thus, if brain damage after whiplash is identified and supported by positive neuroimaging findings and furthermore is proved to be significantly related to impaired cognitive performance in patients, a basis for compensation may be established. Finally, recently there were studies ${ }^{15} 16$ indicating that neuroimaging (SPECT) may detect brain damage as a possible basis for developing cognitive problems. However, to test the proposed brain damage after whiplash as a basis of cognitive problems a closer look at the relation between neuroimaging and neuropsychological findings is needed.

In this study no significant correlations between neuroimaging findings and perform- ance scores of tests of divided attention and working memory could be found. Neither was there a significant correlation between scores of both tests requiring working memory and regional perfusion or metabolism in areas of the brain which have been found to be the site of the working memory system (dorsolateral prefrontal cortex). ${ }^{10}{ }^{11}$ Nor were there significant correlations between the test scores and regional perfusion or metabolism in any area of the brain. Thus the present study hypothesis could not be confirmed. However, the possible limitations of a correlational analysis and the high threshold which was applied in this study should be borne in mind.

Patients in this study averaged below normal performance levels on tasks of divided attention and working memory. In addition, scores for both tasks correlated significantly, confirming one additional hypothesis of this study. Therefore, findings indicate that impaired performance on divided attention and working memory of patients in this study occurred unrelated to any detectable morphological or functional brain damage as assessed by PET or SPECT.

By contrast with morphological or functional brain damage as a basis for cognitive impairment after whiplash injury the present results support the previously suggested relation between the two aspects of psychological functioning - that is, the cognitive and emotional aspects. ${ }^{2}$ The previously shown significant relation between emotional and cognitive functioning ${ }^{2}$ has been corroborated in the present study by the significant correlation between state anxiety (STAI-X1) and test scores of divided attention. A close relation between emotional and cognitive problems may be the basis for a vicious circle leading to symptoms such as irritability, emotional lability, fatigability, poor memory, or concentration, which are considered core symptoms of whiplash injury. ${ }^{134}$ It should be noted, however, that psychological disposition (trait anxiety as assessed by STAI-X2 score) was not significantly correlated with test scores of divided attention or working memory. This further supports previous findings that disposition is not the principal factor influencing symptom development of patients with whiplash injury. ${ }^{25-37}$ Furthermore, results here favour the previously suggested view that pain experience (headache or neck pain), ${ }^{2}$ which is one of the principal symptoms of whiplash injury, ${ }^{134}$ is likely to trigger cognitive problems in these patients. In this study this suggestion is supported by the significant correlation between pain intensity at the time of testing and low scoring on the task of divided attention. 
Overall, the present findings confirm that as yet undetectable physical injury of the cervical spine may trigger the initial symptoms of whiplash (pain) but that pain related psychological (emotional and cognitive) factors may contribute to persistence of symptoms in the long term. This does not support the involvement of a dichotomy of factors but indicates that there is rather a continuum between physical and psychological aspects in the development of the late whiplash syndrome.

In conclusion, the present data do not confirm any relation between regional perfusion or glucose metabolism as indicators of brain damage and impaired divided attention and working memory of patients with whiplash. Thus the previously suggested brain damage in whiplash ${ }^{15-17}$ does not seem to be involved in the development of cognitive problems after whiplash. In addition, based on a more recent research ${ }^{18}$ the usefulness of PET or SPECT as a diagnostic tool in this injury type may be seriously questioned.

We are indebted to Pietro Ballinari, Department of Psychology, University of Berne, for advice on statistical analyses and for help in performing the statistics, Dr Benedikt Blum for help in data analysis, Thomas Berthold, Robert Goldsmith, and Claudia Amstutz for neuroimaging data acquisition, and Dr Sidney Shaw, Department of Clinical Research, University of Berne, for editorial assistance.

1 Spitzer WO, Skovron ML, Salmi LR, et al. Scientific monograph of the Quebec Task Force on whiplash-associated disorders: redefining whiplash and its management. Spine 1995;20(suppl 8):1s-73s.

2 Radanov BP, Sturzenegger M, Di Stefano G. Long-term outcome after whiplash injury: a two years follow-up considering features of accident mechanism, somatic,
radiological and psychosocial findings. Medicine 1995;74: 281-97.

3 Kischka U, Ettlin TM, Heim S, et al. Cerebral symptoms following whiplash injury. Eur Neurol 1991;31:136-40.

4 Radanov BP, Dvorak J, Valach L. Cognitive deficits in patients after soft tissue injury of the cervical spine. Spine patients after soft

5 Ettlin TM, Kischka U, Reichmann S, et al. Cerebral symptoms after whiplash injury of the neck: a prospective clinical and neuropsychological study of whip
Neurol Neurosurg Psychiatry 1992;55:943-8.

6 Keidel M, Yagüez L, Wilhelm H, et al. Prospektiver Verlauf neuropsychologischer Defizite nach zervikozephalem Akzelerationstrauma. Nervenarzt 1992;63:731-40.

7 Radanov BP, Di Stefano G, Schnidrig A, et al. Cognitive functioning after common whiplash: a controlled follow-up study. Arch Neurol 1993;50:87-91.

8 Baddeley A. Working memory. Science 1992;255:556-9.

9 Goldman-Rakic PS. The issue of memory in the study of prefrontal function. In: Thierry A-M, Glowinski J, Goldman-Rakic PS, Christen Y, eds. Motor and cognitive functions of the prefrontal cortex. New York: Springer, 1994:112-21

10 D'Esposito MD, Detre JA, Alsop DC, et al. The neural basis of the central executive system of working memory. Nature 1995;378:279-81.

11 Fiez JA, Raife EA, Balota DA, et al. A positron emission tomography study of the short-term maintenance of verbal information. $\mathcal{f}$ Neurosi $1996 ; 16: 808-22$.
12 Ichise $M$, Chung D-G, Wang $P$, et al. Technetium-99mHMPAO-SPECT, CT and MRI in the evaluation of patients with chronic traumatic brain injury. $7 \mathrm{Nucl} \mathrm{Med}$ 1994;35:217-26.

13 Jacobs A, Put E, Ingles $M$, et al. Prospective evaluation of technetium-99m-HMPAO SPECT in mild and moderate traumatic brain injury. $\mathcal{F}$ Nucl Med 1994;35:942-7.

14 Ommaya $\mathrm{K}$, Genarelli $\mathrm{T}$. Experimental head injury. In: Vinken P, Bruyn G, eds. Handbook of clinical neurology. Amsterdam: North-Holland, 1975:67-90.

15 Otte A, Ettlin TM, Nitzsche EU, et al. PET and SPECT in whiplash syndrome: a new approach to a forgotten brain? $\mathcal{F}$ Whiplash syndrome: a new approach to a forg

16 Otte A, Ettlin T, Fierz L, et al. Parieto-occipital hypoperfusion in late whiplash syndrome: first quantitative SPET study using technetium-99m bicisate (ECD). Eur f Nucl Med 1996;23:72-4.

17 Otte A, Mueller-Brand J, Nitzsche EU, et al. Functional brain imaging in 200 patients after whiplash injury. $\mathcal{F}$ Nucl Med 1997;38:1002.

18 Bicik I, Radanov BP, Schäfer N, et al. FDG-PET and HMPAO-SPECT in patients with late whiplash syndrome. Neurology 1998;51:345-50.

19 Talbot JD, Marret S, Evans AC, et al. Multiple representations of pain in human cerebral cortex. Science 1991;251: $1355-8$

20 Casey KL, Minoshima S, Berger KL, et al. Positron emission tomographic analysis of cerebral structures activated specifically by repetitive noxious heat stimuli. I Neurophysiol 1994;71:802-7.

21 Hirsch SA, Hirsch PJ, Hiramoto $\mathrm{H}$, et al. Whiplash syndrome: fact or fiction? Orthop Clin North Am 1988;19: 791-5.

22 Beck AT, Steer RA. Beck depression inventory. San Antonio: The Psychological Corporation, 1987.

23 Hautzinger M, Bailer M, Worall $\mathrm{H}$, et al. Beck-DepressionsInventar. Bern: Huber Verlag, 1992.

24 Caine ED. The neuropsychology of depression: the pseudodementia syndrome. In: Grant I, Adams KM, eds. Neuropsychological assessment of neuropsychiatric disorders. psychological assessment of neuropsychiatric disorders.

25 Spielberger CD, Gorsuch RL, Lushene RE. Manual for the state-trait anxiety inventory (STAI) test manual form X. Palo Alto: Consulting Psychologists Press, 1970.

26 Laux L, Glanzmann P, Schaffner P, et al. State-TraitAngstinventar. Weinheim: Beltz, 1981.

27 Eysenck MW. Trait anxiety and stress. In: Fisher S, Reason $\mathrm{J}$, eds. Handbook of life stress, cognition and health. Chichester: John Wiley, 1988:467-82.

28 Costa PJ, McCrae RR. Neuroticism, somatic complaints, and disease: is the bark worse than the bite? F Person 1987; 55:299-316.

29 Zimmermann P, North P, Fimm B. Diagnosis of attentional deficits: Theoretical considerations and presentation of a test battery. In: Stachowiak FJ, ed. Developments in the assessment and rehabilitation of brain-damaged patients. Perspectives from a European concerted action. Tübingen: Gunter Narr Verlag, 1993:3-15.

30 Frackowiak RS, Friston KJ. Functional neuroanatomy of the human brain: positron emission tomography: a new neuroanatomical technique. F Anat 1994;184:211-25.

31 Talaraich J, Tournoux P. A co-planar stereotactic atlas of a human brain. Stuttgart: Thieme Verlag, 1988.

32 Blum B. Einsatz des Programms SPM95 ausserhalb von Stimulationsexperimenten [MD-thesis]. Zuerich: University of Zuerich, 1997.

33 Balla JI. The late whiplash syndrome. Aust NZ F Surg 1980; 50:610-4

34 Mayou R, Radanov BP. Whiplash neck injury. F Psychosom Res 1996;40:461-74.

35 Mayou R, Bryant B, Duthie R. Psychiatric consequences of road traffic accidents. BMF 1993;307:647-51.

36 Radanov BP, Di Stefano G, Schnidrig A, et al. Common whiplash-psychosomatic or somatopsychic? 7 Neurol Neurosurg Psychiatry 1994;57:486-90.

37 Radanov BP, Begré S, Sturzenegger M, et al. Course of psychological variables in whiplash injury: a two year follow up with age, gender and education pair-matched patients. Pain 1996;63:429-34. 